\title{
Vitimização por stalking: um estudo sobre a prevalência em estudantes universitários
}

\author{
Mariana Tordin Boen' (iD 0000-0001-9873-3824 \\ Fernanda Luzia Lopes ${ }^{2}$ (iD) 0000-0002-2820-6217
}

'Universidade Estadual Paulista "Júlio de Mesquita Filho", Marília, SP, Brasil. 17502-570

2Universidade São Francisco, Itatiba, SP, Brasil. 13250-000

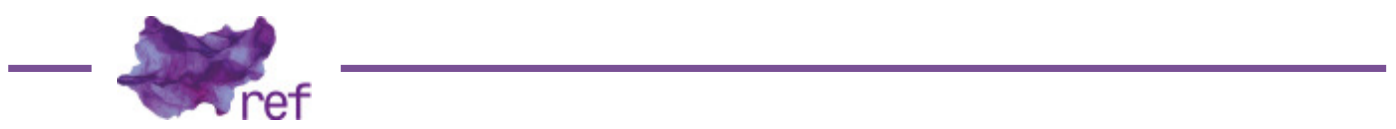

Resumo: O stalking diz respeito a comportamentos de assédio persistentes que se apresentam em formas de comunicação, contato, vigilância e monitorização de um indivíduo. O presente trabalho buscou encontrar dados referentes à vitimização por stalking em 205 estudantes universitários de uma universidade do interior de São Paulo, utilizando o Inventário de Vitimação por Stalking (IVS) desenvolvido em Portugal, partindo da escassez de estudos realizados sobre o tema no Brasil. Os dados coletados por meio do IVS foram analisados pela estatística descritiva, considerando o grupo de participantes em seu total e também divididos de acordo com sexo, idade, estado civil e curso, estabelecidos pelos dados obtidos com o questionário de identificação. Os resultados obtidos revelaram que a maioria dos participantes da pesquisa $(50,4 \%, n=104)$ já vivenciaram uma experiência de stalking, de acordo com a definição apresentada pelo instrumento utilizado (IVS).

Palavras-chave: assédio persistente; adultos; ocorrência; impactos psicossociais; perseguição obsessiva

Stalking Victimization: A Study about the Prevalence in College Students

Abstract: Stalking refers to persistent harassment behaviors that occur in forms of communication, contact, surveillance, and monitoring of an individual. This study aimed to find data on victimization by stalking in 205 college students at a university in an inland city of São Paulo, using the Inventário de Vitimação por Stalking (IVS) developed in Portugal, due to the scarcity of studies on the subject in Brazil. The data collected through the IVS were analyzed using descriptive statistics, considering the group of participants in its total and divided according to gender, age, marital status and course of study, established by the data obtained from the questionnaire of identification. The results revealed that most survey participants $(50,4 \%, n=104)$ have experienced stalking according to the definition established by the IVS. Key words: Stalking; Adults; Frequency; Psychosocial impact; Obsessive attention

\section{Introdução'}

Nos últimos anos, o interesse em torno das pesquisas relacionadas à violência contra a mulher tem aumentado. São diversas as produções acadêmicas, e certos temas têm conquistado maior atenção científica - como é o caso dos comportamentos de stalking. As diferenças existentes nos dados de vitimização entre homens e mulheres justificam a possibilidade de se levantar discussões em torno da relação destes à condição de gênero, apesar de ser indispensável que se considere também a vitimização masculina.

É possível definir o stalking como uma maneira de violência relacional (Laura DE FAZIO, 2009; William CUPACH; Brian SPITZBERG, 2004 apud Marlene MATOS; Helena GRANGEIA; Célia FERREIRA; Vanessa AZEVEDO, 201 1b, p. 17) que diz respeito a:

' Pesquisa originalmente realizada como trabalho de conclusão do curso de graduação em Psicologia, no ano de 2016. 
Um padrão de comportamentos de assédio persistente, que se traduz em formas diversas de comunicação, contato, vigilância e monitorização de uma pessoa-alvo. Estes comportamentos podem consistir em ações rotineiras e aparentemente inofensivas (ex. oferecer presentes, telefonar frequentemente, deixar mensagens escritas) ou em ações inequivocamente intimidatórias (ex. perseguição, mensagens ameaçadoras). O conjunto destes comportamentos, pela sua persistência e contexto de ocorrência, constitui-se como uma verdadeira campanha de assédio que, muitas vezes, afeta significativamente o bem-estar da vítima. (Helena GRANGEIA; Marlene MATOS, 2010; MULLEN; PURCELL, 2001; Lorraine SHERIDAN; Eric BLAAUW; Graham M. DAVIS, 2003, apud MATOS et al., $2011 \mathrm{~b}$, p.17)

Na sociedade moderna, o interesse a respeito do stalking começou a aparecer na academia a partir da década de noventa. Pesquisas a respeito do tema foram produzidas, por meio das quais tornou-se claro que se tratava de um problema social, e não apenas de casos de celebridades isolados fortalecidos pela ampla cobertura da mídia (Lorraine SHERIDAN; Eric BLAAUW; Graham M. DAVIES, 2003).

Apesar da definição apresentada, existem diversas discussões sobre quais elementos ou comportamentos realmente compreendem o stalking, o que gera muitas divergências e dificuldades de definição. Segundo Sheridan et al. (2003), trata-se de um crime - quando assim tipificado pela lei - que normalmente consiste na repetição de comportamentos de rotina, comuns e habituais.

Da mesma maneira, Matos et al. (201 1b) apontam para o quão comuns, e com frequência até mesmo desejáveis, são alguns dos comportamentos considerados na definição de stalking como é o caso de formas de flerte e demonstração de interesse aceitos e esperados pela própria sociedade. Tais condutas agressivas de aproximação são com frequência apresentadas de maneira positiva pelos meios de comunicação de massa (Allan JOHNSON, 2005 apud Eric LAMBERT; Brad SMITH; James GEISTMAN; Terry CLUSE-TOLAR, 2013, p. 203), especialmente por meio de representações em filmes - como é o caso dos filmes hollywoodianos, nos quais a persistência é apresentada como forma de conquistar as pessoas, reforçando a ideia de determinados comportamentos insistentes como vias aceitáveis e até esperadas de conquista (LAMBERT et al., 2013). Letras de música também podem ser consideradas dentro dessa perspectiva, em um contexto mais amplo e internacional, com canções famosas e antigas como Every Breath You Take - The Police, e nacionais - sendo possível pensar em algumas músicas sertanejas, por exemplo.

Esses fatores acabam por gerar uma grande dificuldade em que se reconheçam alguns comportamentos como sendo problemáticos, visto "que desafiam algumas crenças e normas culturalmente enraizadas" (Helena GRANGEIA; Marlene MATOS, 2010 apud MATOS et al., $2011 \mathrm{~b}$, p. 18). Além disso, os pesquisadores discutem onde se encontra a linha que separa uma genuína manifestação de afetos de uma atitude não apropriada e intrusiva para o alvo dos mesmos $(\mathrm{H}$. Colleen SINCLAIR; Irene Hanson FRIEZE, 2000), pensando principalmente que "a percepção dessas condutas varia 'não só de pessoa para pessoa, mas também de relação para relação e de cultura para cultura'" (William CUPACH; Brian SPITZBERG, 2002 apud MATOS et al., $2011 \mathrm{~b}, \mathrm{p}$. 19).

As definições legais do fenômeno variam de acordo com a legislação do país em questão, mas comumente identificam o stalking por algumas características principais, sendo elas: “(a) intencional (b) padrão de comportamentos repetitivos para uma ou mais pessoas (c) que são indesejados (d) resultam em medo, ou algo que uma pessoa 'razoável' (ou júri) veria como amedrontador ou ameaçador" (Brian SPITZBERG; William CUPACH, 2007, p. 66). A principal crítica direcionada às definições legais diz respeito à exigência de que as vítimas admitam sentir medo (ou sintam-se ameaçadas) para que suas experiências sejam social e legalmente validadas, pois o medo, como outras várias emoções, é socialmente produzido (Arlie Russell HOCHSCHILD, 1983 apud Noella DIETZ; Patricia Yancey MARTIN, 2007, p. 752). Estudos como os realizados por Dietz e Martin (2007), cujos resultados demonstraram que um quarto das oito mil mulheres adultas participantes que alegaram já terem sido vítimas de stalking não sentiram medo como consequência da experiência, dão suporte a tais críticas.

A complexidade e diversidade dos comportamentos de stalking justificam o interesse multidisciplinar pelo tema (SHERIDAN et al., 2003), que passa especialmente pela psicologia, psiquiatria, sociologia e direito. Trata-se de um fenômeno que exige contextualização, sendo impossível defini-lo a partir de um comportamento único, dada a sua característica intimidatória. Portanto, é ainda mais difícil definir o stalking em locais nos quais a sociedade não o reconhece como uma forma de violência relacional, porque torna a questão ainda mais sensível aos meios de validação social, fazendo com que os fatores socioculturais influenciem na legitimação do que pode constituir uma ofensa (MATOS et al., $2011 \mathrm{~b}, \mathrm{p} .18$ ).

Traçando um breve paralelo sobre a característica intimidatória do Stalking e a violência relacional, compreende-se que a naturalização do papel da mulher como submissa às situações domésticas (nascer, crescer, casar, cuidar da prole e honrar ao lar e ao marido) é comum na maioria das sociedades, principalmente àquelas com determinantes eurocêntricas. A essa submissão, destaca-se a ideia, ainda corrente, do homem provedor e regulador da economia 
doméstica, haja vista a supervalorização do trabalho extra-doméstico, um dos produtos do patriarcado (Claudete MONTEIRO; Ivis SOUZA, 2007; Silvia MARQUES; Fernanda PACHECO, 2009).

Nesse contexto, é possível pensar a naturalização de certos comportamentos e a pouca importância apresentada aos mesmos através do sociólogo Pierre Bourdieu e as discussões realizadas pelo autor em relação à dominação masculina.

[...] é preciso assinalar não só que as tendências à "submissão", dadas por vezes como pretexto para "culpar a vítima", são resultantes das estruturas objetivas, como também que essas estruturas só devem sua eficácia aos mecanismos que elas desencadeiam e que contribuem para sua reprodução. O poder simbólico não pode se exercer sem a colaboração dos que the são subordinados e que só se subordinam a ele porque o constroem como poder [...] temos que registrar e levar em conta a construção social das estruturas cognitivas que organizam os atos de construção do mundo e de seus poderes. Assim se percebe que essa construção prática, longe de ser um ato intelectual consciente, livre, deliberado de um "sujeito" isolado, é, ela própria, resultante de um poder, inscrito duradouramente no corpo dos dominados sob forma de esquemas de percepção e de disposições (a admirar, respeitar, amar etc.) que o tornam sensível a certas manifestações simbólicas do poder (Pierre BOURDIEU, 1998, p. 52/53).

No Brasil, o crime de stalking não é legalmente tipificado. Porém o projeto de Novo Código Penal propõe, através da PL 5419/09, a inclusão de uma nova forma de crime definido e punido de acordo com o seguinte artigo:

Art. 146- A. Perseguir alguém de maneira insidiosa, causando dano à integridade material ou moral da vítima e restringindo a sua locomoção ou forma de vida. Pena: reclusão, de 01 a 04 anos, além da obrigação de manutenção de distância razoável da vítima, determinada pelo juiz, se necessário, ou multa. (BRASIL, 2009)

Em casos que se relacionem a violência doméstica e familiar contra a mulher, ou seja, ocorridas no âmbito da unidade doméstica, da família ou em qualquer relação íntima de afeto, a lei $n^{\circ} 11.340$, conhecida como lei Maria da Penha, apresenta como uma das formas de violência, a violência psicológica, na qual é possível compreender determinados comportamentos envolvidos no stalking.

Esses comportamentos podem se desenvolver em termos de frequência dos acontecimentos, assim como em relação à seriedade dos mesmos, conforme o tempo de duração da experiência. Além disso, pode culminar ou se relacionar a outras formas de violência mais facilmente reconhecidas, como física, a psicológica e a sexual (Helena GRANGEIA; Marelene MATOS, 2010; Paul E. MULLEN; Rosemary PURCELL, 2001; Lorraine SHERIDAN; Eric BLAAUW; Graham M. DAVIS, 2003, apud MATOS et al., 2011 b, p. 17).

Como referenciado, os comportamentos incluídos nas definições de stalking são comumente comportamentos banais, cotidianos - muitas vezes até mesmo esperados. Quando reconhecidamente agressivos ou violentos, esses comportamentos também podem ser considerados comportamentos antissociais genéricos como humilhações, xingamentos e calúnias. A especificidade do stalking se dá, portanto, especialmente pela recorrência de tais comportamentos, ao ponto que se tornam invasivos e passam a gerar diferentes consequências e impactos na vida de quem os vivencia. Além disso, tais condutas se dão em um contexto social específico, no caso a sociedade patriarcal, machista e misógina, na qual o gênero demarca diferenças importantes na construção e socialização do ser homem e ser mulher. Essa colocação se mostra indispensável para ser possível pensar o stalking através da perspectiva de gênero - considerando o alto índice de vitimização por parte das mulheres.

Segundo Marcela Lagarde, "o gênero é uma construção simbólica e contém o conjunto de atributos designados às pessoas a partir do sexo". Para a autora, o gênero implica em diversos aspectos da vida do sujeito, homem ou mulher, como suas atividades, sua intelectualidade, sua afetividade, subjetividade, valores, linguagens, etc. (LAGARDE, 1996, p. 12). Em outras palavras, 0 lugar social que o indivíduo ocupa a partir do gênero que lhe é atribuído influencia toda a sua vivência como sujeito, todas as suas experiências sociais e até mesmo relacionais.

Dessa forma, o relacionamento entre o stalker e a vítima é de grande importância, frente aos dados de algumas pesquisas (Jessica HARRIS, 2000; Lorraine SHERIDAN; Graham M. DAVIES, 2001 ; Kris MOHANDIE; J. Reid MELOY; Mila GREEN-MCGOWAN; Jenn WILLIAMS, 2006; Patricia TJADEN; Nancy THOENNES, 1998; Eric BLAAUW; Frans W. WINKEL; Ella ARENSMAN; Lorraine SHERIDAN; Adriënne FREEVE, 2002; Michele PATHÉ, 2002 apud Michelle WELLER; Lorraine HOPE; Lorraine SHERIDAN, 2012) que indicam os incidentes de stalking praticados por indivíduos que tiveram alguma forma de relação próxima ou íntima com a vítima como sendo mais comuns, mais propensos a envolver violência ou ameaça física e a persistir por mais tempo, além dos indivíduos serem menos propensos a sofrer condenações legais por seus atos. Aqui, é possível questionar a ideia existente em torno do relacionamento, o velho ditado popular de que "em briga de marido e mulher não se mete a colher". Quais os impactos dessa percepção, tanto no reconhecimento da violência, como até mesmo nas consequências sofridas pelos perpetuadores? 
Algumas pesquisas apontam que os comportamentos de stalking que envolvem sujeitos que foram parceiros íntimos podem vir a ser associados a um aumento da probabilidade de violência, assim como da duração da experiência, especialmente em casos de uma ligação emocional intensa do ofensor com a vítima (Frank R. FARNHAM; David V. JAMES; Paul CANTRELL, 2000; Barry ROSENFELD, 2004; Katja BJÖRKLUND; Helinä HÄKKÄNEN-NYHOLM; Lorraine SHERIDAN; Karl ROBERTS, 2010). Patricia Tjaden e Nancy Thoennes (1998) indicaram que 59\% das mulheres vítimas de stalking o sofriam por parte de um parceiro íntimo e $81 \%$ dessas mulheres também foram fisicamente agredidas. Já de acordo com Brian Spitzberg e William Cupach (2007), aproximadamente $80 \%$ dos stalkers são conhecidos da pessoa que eles perseguem. Ainda, Rosemary Purcell, Michele Pathé e Paul E. Mullen (2000 apud WELLER et al., 2012) apresentam que, aproximadamente, $50 \%$ dos casos de stalking envolvendo ofensores desconhecidos com frequência possuem a duração de apenas alguns dias e, comumente, não são mantidos por mais de duas semanas.

Ao se falar sobre prevalência em relação a stalking em estudos anteriores, é indispensável considerar a definição utilizada, visto que a mesma impacta diretamente nos números obtidos. Uma meta-análise realizada por Spitzberg e Cupach (2007) apresentou que a prevalência de stalking variou entre $2 \%$ a $13 \%$ para homens e $8 \%$ a $32 \%$ para mulheres. Na Inglaterra os números apontam que uma em cada cinco mulheres irá passar pela experiência (John FLATLEY; Chris KERSHAW; Kevin SMITH; Rupert CHAPLIN; Debbie MOON, 2010), enquanto na Itália, um relatório do Ministério da Justiça (2014) indicou que a taxa de prevalência dentre a população geral é de $11,2 \%$. Já em Portugal, os dados indicam uma vitimização de $25 \%$ para as mulheres e de $13,3 \%$ para os homens (MATOS; GRANGEIA; FERREIRA; AZEVEDO, 2011 a).

Consequentemente, tal experiência pode gerar implicações relacionadas à saúde psicológica ou a mudanças no estilo de vida do sujeito. Entretanto, ainda pouco se sabe a respeito das intervenções relacionadas a situações de stalking. Quais seriam as melhores respostas?

Apresenta-se que alguns tipos de respostas seriam mais eficazes do que outras a longo prazo. Dentre elas, evitar o stalker - as chamadas "respostas de evitamento", possuem uma "maior tendência de desgastar o interesse do autor" (William CUPACH; Brian SPITZBERG, 2000 apud Terry GOLDSWORTHY; Matthew RAJ, 2014, p. 186). Por outro lado, as "respostas de negociação", assim como as "respostas de confrontamento" são vistas como contraproducentes, pois podem reforçar os comportamentos indesejados - caso a intenção do indivíduo seja causar perturbação, atitudes nas quais o alvo demonstre raiva ou retaliação comunicará ao stalker que seu comportamento está causando o efeito que deseja (William CUPACH; Brian SPITZBERG, 2004; Leila DUTTON; Barbara A. WINSTEAD, 2011 apud GOLDSWORTHY; RAJ, 2014). Os resultados de um estudo realizado por Leila Dutton e Barbara Winstead (201 1) sugerem que a combinação de evitação por parte do alvo ${ }^{2}$ e o passar do tempo podem fornecer uma oportunidade ao indivíduo que persegue de superar a relação, cessando os comportamentos. Além disso, é importante que as vítimas sejam claras e diretas sobre o fim do relacionamento com seus ex-parceiros, evitando que haja espaço para duplas interpretações.

Desta forma, este estudo tem por objetivo iniciar uma investigação sobre a prevalência do fenômeno de stalking em território nacional, incentivar pesquisas referentes ao tema e levantar questionamentos acerca da definição de stalking, assim como quais são as suas características e de que forma se apresenta, através de uma pesquisa realizada em estudantes universitários, visto que não foram encontrados dados prévios de pesquisas relacionadas à temática na literatura nacional.

\section{Método de pesquisa}

\section{Sujeltos}

Participaram da presente pesquisa 205 estudantes do ensino superior de uma universidade particular da cidade de Campinas, interior do estado de São Paulo, distribuídos entre os cursos de psicologia $(51 \%, n=103)$, farmácia $(23,8 \%, n=48)$ e engenharias $(25,2 \%, n=51)$. Quanto ao sexo, $68,3 \%(n=140)$ dos participantes eram do sexo feminino. Desses participantes, $82,5 \%(n=168)$ eram solteiros, $13,7 \%(n=28)$ casados, $2,9 \%(n=6)$ estavam em união estável e $1 \%(n=2)$ eram divorciados. A idade dos participantes variou entre 18 e 58 anos, com média de 24,7 anos ( $D P=$ 6,44). A amostra foi selecionada por conveniência em turmas dos cursos citados da universidade, motivo da não paridade entre sexos.

\section{Material}

Utilizou-se o Inventário de Vitimação por Stalking (IVS), construído por Matos et al. (2011 a), para avaliação da prevalência da vitimização por stalking. Sua população alvo são indivíduos

\footnotetext{
2 Tradução livre para "target avoidance".
} 
de ambos os sexos, com idade igual ou superior a 16 anos. O IVS foi desenvolvido após uma revisão e uma análise dos instrumentos existentes em um panorama externo à Portugal.

Para operacionalizar a definição do fenômeno stalking, selecionaram-se onze comportamentos que a literatura internacional observa como representantes das experiências de stalking, sendo eles: perseguição (carro, moto, a pé etc.); tentativas de contato (cartas, bilhetes, telefonemas etc.); ameaça contra si próprio ou a pessoas próximas; filmagem ou fotografia sem autorização; coisas vasculhadas, roubadas ou apoderadas; invasão de propriedade ou entrada forçada na residência; ir a locais que a pessoa frequenta; ameaçar fazer mal a si mesmo (ex. suicidar-se); vigiar ou pedir para alguém fazê-lo; agressão; e agredir ou prejudicar pessoas próximas. Visto que o vocabulário português não possui palavra que compreenda na íntegra o que significa o conceito de stalking, adotou-se a referência como "assédio persistente" (MATOS et al., 201 la). Além disso, como o IVS foi desenvolvido originalmente em Portugal, para aplicação em universidade brasileira foram alteradas algumas palavras que pudessem vir a causar dificuldade na compreensão de leitura, o que não alterou o conteúdo do instrumento.

\section{Procedimento}

Este projeto foi aprovado pelo Comitê de Ética em Pesquisa.

A aplicação do instrumento (IVS) foi realizada em grupo. Os objetivos foram esclarecidos para os participantes em sala de aula e o Termo de Consentimento Livre e Esclarecido foi distribuído. Após a assinatura dos termos, o instrumento foi explicado e entregue; cada indivíduo levou, em média, 10 minutos para responder ao IVS - sendo que nem todos os participantes terminaram o preenchimento do instrumento ao mesmo tempo.

\section{Resultados e dlscussão}

Os resultados obtidos por meio das estatísticas descritivas puderam indicar a prevalência da vitimização por stalking. Assim, dentre os 205 estudantes que participaram dessa pesquisa, observouse que a maioria $(50,7 \%, n=104)$ declarou ter vivenciado alguma situação que se enquadra na definição "consiste na experiência de alguém que é alvo, por parte de outra pessoa, de um interesse e uma atenção continuados, mas indesejados" de assédio persistente utilizada pelo IVS (MATOS et al., 201 1a, p. 75), e são estes participantes que se autodeclararam vítimas que serão o foco dessa discussão. Desses sujeitos, $79,8 \%(n=83)$ eram mulheres e $20,2 \%(n=21)$ eram homens.

As análises realizadas pelo método estatístico chi-quadrado demonstraram que a questão de ser mulher está significativamente relacionada à condição para ser vítima de stalking, $X^{2}(1$, $n=125)=19,73, p<0,01$. Tais resultados se apresentam semelhantes aos resultados encontrados na literatura internacional, os quais também apontam que a maioria das vítimas de stalking são mulheres, sendo que a chance de vivenciar a experiência de vitimização é entre duas e quatro vezes maior para mulheres do que para homens (Patricia TJADEN; Nancy THOENNES, 1998; SPITZBERG; CUPACH, 2007).

Ainda, em relação aos sujeitos que afirmaram terem sido vítimas, 49,5\% $(n=51)$ vivenciaram a experiência mais de uma vez ao longo da vida, sendo que a maior parte $(40 \%)(n=20)$ passou pela experiência de stalking duas vezes, seguido de $26 \%(n=13)$ que vivenciaram tal situação por três vezes.

Dentre os participantes que afirmaram terem sido vítimas de stalking, $77,5 \%(n=79)$ apontaram que, em sua experiência mais marcante, o stalker era um homem, resultado que também corrobora com a literatura internacional (Christine M. ENGLEBRECHT; Bradford W. REYNS, 2011 ; SHERIDAN et al., 2003; Brian SPITZBERG, 2002 apud LAMBERT et al., 2013). Quanto ao relacionamento vítima-agressor, como pode ser visto na Tabela 1 , a maior parte $(47,1 \%)$ era "um conhecido, colega, amigo, vizinho ou familiar", seguido de "alguém com quem teve uma relação de intimidade que já terminou" (28,8\%), enquanto $12,5 \%$ era uma pessoa desconhecida.

Esses números podem ser inicialmente questionados por, primeiramente, abordarem relações particularmente distintas em categorias semelhantes, como é o caso de se colocar "conhecido, colega, amigo, vizinho ou familiar" em uma mesma opção de resposta. Além disso, os dados encontrados na literatura internacional também apontam para uma diferença existente na percepção da gravidade de comportamentos quando estes são realizados por ex-parceiros íntimos, parecendo existir uma menor preocupação do que quando as mesmas condutas partem de sujeitos desconhecidos ou estranhos à vítima (Lorraine PHILLIPS; Ryan QUIRK; Barry ROSENFELD; Maureen O'CONNOR, 2004; Adrian J. SCOTT; Rebecca LLOYD; Jeff GAVIN, 2010; Adrian J. SCOTT; Lorraine SHERIDAN, 2011 apud WELLER et al., 2012).

Ainda assim, mostra-se relevante refletir a respeito dos resultados que apontam para uma maior vitimização perpetrada por pessoas próximas à vítima (como um conhecido, colega, amigo, vizinho ou familiar) e um ex-parceiro da mesma. A independência feminina e seu sucesso econômico na sociedade atual coloca as mulheres em um lugar de maior risco de vitimização (Pierpaolo 
MARTUCCI; Rita CORSA, 2009 apud Andrea CAPUTO, 2013). Essas mudanças passaram a alterar a performance dos papéis sociais esperados, retirando a mulher do lugar submisso que lhe é atribuído. A construção da masculinidade em torno da dominação e posse, enquanto a feminilidade se respalda na submissão, permite que se pense, a partir de Bourdieu, sobre a relação que se constrói socialmente entre a binaridade dos gêneros - especialmente de que forma essa relação e a sexualidade se dão para ambas as partes.

[...] Uma sociologia política do alto sexual faria ver que, como sempre se dá em uma relação de dominação, as práticas e as representações dos dois sexos não são, de maneira alguma, simétricas. Não só porque as moças e os rapazes têm, até mesmo nas sociedades euroamericanas de hoje, pontos de vista muito diferentes sobre a relação amorosa, na maior parte das vezes pensada pelos homens com a lógica da conquista [...], mas também porque o ato sexual em si é concebido pelos homens como uma forma de dominação, de apropriação, de 'posse'. Daí a distância entre as expectativas prováveis dos homens e das mulheres em matéria de sexualidade - e os mal-entendidos que deles resultam, ligados a más interpretações de 'sinais', às vezes deliberadamente ambíguos ou enganadores. (BOURDIEU, 1998, p. 29-30)

Tabela 1 - Distribuição dos sujeitos por relacionamento vítima-stalker

\begin{tabular}{|c|c|c|}
\hline Resposta & $n$ & $\%$ \\
\hline $\begin{array}{l}\text { Alguém com quem tem atualmente uma relação de intimidade (ex. } \\
\text { parceiro/a, marido/mulher) }\end{array}$ & 01 & 01,0 \\
\hline $\begin{array}{l}\text { Alguém com quem teve uma relação de intimidade que já terminou } \\
\text { (ex. ex-parceiro/a, ex-marido/mulher) }\end{array}$ & 30 & 28,8 \\
\hline Um/a conhecido/a, colega, amigo/a, vizinho/a ou familiar & 49 & 47,1 \\
\hline Alguém que conheceu através da Internet & 08 & 07,7 \\
\hline Um/a desconhecido/a & 13 & 12,5 \\
\hline Outro & 03 & 02,9 \\
\hline Total & 104 & 100,0 \\
\hline
\end{tabular}

Nos casos em que houve $(28,8 \%)$ ou há $(1,0 \%)$ relacionamento íntimo com o stalker, dos 30 sujeitos que responderam à pesquisa, $13,3 \%(n=4)$ dos comportamentos de stalking ocorreram antes de iniciar a relação amorosa, $53,3 \%(n=16)$ durante a relação amorosa e $76,7 \%(n=23)$ depois de terminada a relação amorosa, sendo que em alguns casos os comportamentos aconteceram em dois ou mais momentos da relação.

Dentre os sujeitos que passaram por uma experiência de assédio persistente, $87,1 \%(n=88)$ não estavam mais vivenciando a experiência na época em que a pesquisa foi realizada, enquanto $12,9 \%(n=13)$ continuavam passando pela situação no momento do estudo. Neste primeiro caso, $30 \%(n=24)$ foram vítimas durante o último ano, enquanto $70 \%(n=56)$ foram vítimas há mais de um ano. Uma pesquisa realizada para o National Crime Victimisation Survey in the United States, no ano de 2006, apresentou algumas percepções de vítimas em relação ao motivo pelo qual o stalker desistiu de seus comportamentos de assédio. As razões mais citadas no estudo foram intervenção policial (polícia alertar o autor), intervenção da própria vítima (falar com o stalker), intervenção de pessoa próxima à vítima. Ainda, aproximadamente um décimo das vítimas relacionaram que o fim dos comportamentos intrusivos se deu após terem obtido alguma forma de medida protetiva que obrigasse legalmente o autor a manter certa distância (Katrina BAUM; Shannan CATALANO; Michael RAND; Kristina ROSE, 2009). De acordo com as pesquisas, a real efetividade das respostas não é constante, ou seja, sua eficácia se apresenta variável (DUTTON; WINSTEAD, 2011).

Quanto aos comportamentos que ocorrem com frequência nas experiências de assédio persistente, considerando a possibilidade de uma pessoa ter passado por mais de uma forma de comportamento, $41,7 \%(n=43)$ dos sujeitos responderam que foram perseguidos (ex. a pé, de carro, de moto), $86,4 \%(n=89)$ passaram por tentativas de contato (como envio de cartas, bilhetes, e-mails, telefonemas), $12,6 \%(n=13)$ foram ameaçados ou tiveram pessoas próximas ameaçadas, $47,6 \%(n=49)$ responderam que o stalker apareceu em locais que costumavam frequentar (ex. café, supermercado), $17,5 \%(n=18)$ dos stalkers ameaçaram fazer mal a si mesmos (ex. suicidar- 
se), $30,1 \%(n=31)$ foram vigiados pelo stalker ou por alguém a mando do mesmo e $14,6 \%(n=15)$ foram alvo de outras formas de comportamento. Os dados são apresentados na Tabela 2.

Como a maioria dos stalkers costumam ser ex-parceiros das vítimas, é sabido que comportamentos insistentes possam ser vistos como esforços legítimos para recuperar o relacionamento perdido. De acordo com Goldsworthy e Raj (2014), como foi sugerido por um especialista em segurança, considera-se recomendável que a vítima se posicione de forma clara e não ambígua em relação as suas intenções sobre o término do relacionamento, evitando assim casos em que um simples gesto ou linguagem pouco claros façam com que o indivíduo acredite que seus comportamentos possam vir a reestabelecer uma relação.

Tabela 2 - Comportamentos apresentados pelo stalker

\begin{tabular}{lcc}
\hline Comportamento & $n$ & $\%$ \\
\hline Perseguição (carro, moto, a pé etc.) & 43 & 41,7 \\
Tentativas de contato (cartas, bilhetes, telefonemas etc.) & 89 & 86,4 \\
Ameaça contra si próprio ou à pessoas próximas & 09 & 8,7 \\
Filmagem ou fotografia sem autorização & 06 & 6,8 \\
Coisas vasculhadas, roubadas ou apoderadas & 06 & 5,8 \\
Invasão de propriedade ou entrada forçada na residência & 03 & 2,9 \\
Ir a locais que a pessoa frequenta & 49 & 47,6 \\
Ameaçar fazer mal a si mesmo (ex. suicidar-se) & 18 & 17,5 \\
Vigiar ou pedir para alguém fazê-lo & 31 & 30,1 \\
Agressão & 09 & 8,7 \\
Agredir ou prejudicar pessoas próximas & 05 & 4,9 \\
Outras formas de comportamento & 15 & 14,6 \\
\hline
\end{tabular}

Dentre os indivíduos agredidos (8,7\%), a forma de agressão sofrida foi descrita como agressões físicas, verbais, sexuais e psicológicas. Já os outros comportamentos de que foram alvo (14,6\%), os participantes relataram "assédio sexual", "chantagem emocional, assédios de raiva", "chantagem psicológica", "convites para sair, perguntas indiscretas, olhares, presentes", "tentativa de invasão de residência de uma amiga", "gaslighting"3, "invasão de todas as redes sociais/e-mail, excesso de mensagens insistentes, buscou manter relações com os familiares da vítima", "perturbou familiares com o propósito de conseguir contato", envio de presentes e tentativas de toque.

Quanto à frequência dos comportamentos de assédio persistente, $44,7 \%(n=46)$ respondeu que ocorriam/ocorrem semanalmente, $37,9 \%(n=39)$ diariamente, seguidos de $9,7 \%(n=10)$ mensalmente e $7,8 \%(n=8)$ menos de uma vez por mês. No que diz respeito à duração do interesse, $1,9 \%(n=2)$ foi alvo dos comportamentos de stalking por menos de duas semanas, $25,2 \%(n=26)$ de 2 semanas a 1 mês, 30,1\% $(n=31)$ de 1 a 6 meses, 19,4\% $(n=20)$ de 6 a 12 meses, 12,6\% $(n=$ 13) de 1 a 2 anos e $10,7 \%(n=11)$ por mais de 2 anos. Stalkers desconhecidos aparecem na literatura como menos propensos a continuar os comportamentos de contato, sendo que aproximadamente $50 \%$ dos casos envolvendo desconhecidos tipicamente duraram apenas alguns dias e normalmente não se estenderam por um período maior que duas semanas (Rosemary PURCELL; Michele PATHÉ; Paul E. MULLEN, 2004 apud WELLER et al., 2012).

Ao se associar os dados de frequência de comportamento ao tipo de relação existente entre a vítima e o stalker, as experiências que duraram "de 1 a 6 meses" tiveram, em $35,5 \%$ dos

${ }^{3}$ O termo "gaslighting", que se originou em uma filme chamado "Gaslight", é utilizado atualmente para nomear uma forma de manipulação emocional em que o perpetuador tenta, não necessariamente de forma consciente, induzir em alguém a sensação de que suas reações, percepções, memórias e/ou crenças estão erradas e completamente infundadas, gerando muitas vezes a sensação de loucura em quem sofre a experiência (Kate ABRAMSON, 2014). 
casos $(n=11)$, um stalker que era "alguém com quem teve uma relação de intimidade que já terminou", igualmente a "um conhecido, colega, amigo, vizinho ou familiar" $(35,5 \%, n=11)$. 0 período "de 2 semanas a 1 mês" esteve relacionado, na maior parte dos casos, a "um conhecido, colega, amigo, vizinho ou familiar" ( $42,3 \%, n=11)$, seguido de "um desconhecido" $(26,9 \%, n=7)$.

Como mostra a literatura, o stalking é muito mais comum do que se acreditava e seus prejuízos não se limitam apenas à vítima, estendendo-se à sociedade (LAMBERT et al., 2013). Para se compreender como e se a experiência de assédio persistente afetou a vida dos indivíduos, dividiu-se o impacto em diferentes áreas. No desempenho profissional/acadêmico, $48 \%$ dos participantes responderam que não foram afetados, $17,6 \%$ quase nada afetados, $22,5 \%$ um pouco afetados, 7,8\% muito afetados e 3,9\% muitíssimo afetados. Já com relação à saúde física, $41,7 \%$ responderam que não foram afetados, $12,6 \%$ quase nada, $25,2 \%$ um pouco, $13,6 \%$ muito e 6,8\% foram muitíssimo afetados. A maior interferência se mostrou em relação à saúde psicológica, na qual $18,3 \%$ responderam não terem sido afetados, $11,5 \%$ quase nada, $31,7 \%$ um pouco, $20,2 \%$ muito e $18,3 \%$ muitíssimo.

Ainda em relação aos impactos, o IVS também busca averiguar a interferência do comportamento de stalking nas relações da vítima com as outras pessoas de seu meio. Os resultados aqui obtidos indicaram que $34 \%$ não se sentiram afetados, $14,6 \%$ quase nada afetados, $26,2 \%$ um pouco, $19,4 \%$ muito e 5,8\% muitíssimo afetados. Quanto às relações íntimas, $37,3 \%$ relataram não terem sido afetados, $12,7 \%$ quase nada, $22,5 \%$ um pouco, $15,7 \%$ muito afetados e $11,8 \%$ muitíssimo afetados.

A questão econômica/financeira apareceu com a menor interferência, sendo que a maior parte $(79,6 \%)$ não se sentiu afetada, $9,7 \%$ quase nada, $6,8 \%$ um pouco, $1,9 \%$ muito e $1,9 \%$ muitíssimo. Por fim, no que diz respeito à interferência em relação ao estilo de vida/comportamento, $25,5 \%$ responderam que não foram afetados, $14,7 \%$ quase nada, $34,3 \%$ um pouco, $14,7 \%$ muito e 10,8\% muitíssimo afetados.

As pesquisas sustentam o stalking como algo traumático para as vítimas, que podem sofrer consequências econômicas, psicológicas, sociais e físicas (Beth BJERREGAARD, 2000; SHERIDAN et al., 2003; SPITZBERG; CUPACH, 2007). Segundo alguns autores (Katrina BAUM; Shannan CATALANO; Michael RAND, 2009; Beth BJERREGAARD, 2000; Tracey BUDD; Joanna MATTINSON, 2000; Alana M. NICASTRO; Amber V. COUSINS; Brian SPITZBERG, 2000; BAUM et al., 2003; Chris BREWSTER, 1998; Bonnie S. FISHER; Francis T. CULLEN; Michael G. TURNER, 1999; SINCLAIR; FRIEZE, 2005, apud GOLDSWORTHY; RAJ, 2014), os métodos mais comuns utilizados pelas vítimas de stalking para frustrar os comportamentos intrusivos consistem em mudar as atividades diárias, pedir para que a pessoa pare com o seu comportamento, evitar certas pessoas ou lugares, desligar os telefonemas, contar com a ajuda de familiares ou amigos, argumentar ou tentar argumentar com o stalker, evitar ou tentar evitar o stalker, e ignorar ou tentar ignorar o stalker, sendo importante ressaltar que essas respostas raramente se dão independentemente.

Muitos indivíduos respondem à atenção indesejada de formas indiretas, como agir de maneira agradável ou esperar que, com o tempo, o stalker naturalmente desista. Na verdade, 'agir de maneira agradável' foi, em um estudo realizado tanto com vítimas como com os perseguidores, a resposta dada com maior frequência - tanto pelas vítimas quanto pelos autores - frente às experiências de comportamentos persecutórios. Segundo as autoras, tais resultados podem ter relação com uma tendência a evitar conflitos que possam magoar os sentimentos dos ex-parceiros românticos (DUTTON; WINSTEAD, 2011). Porém, pode-se também levantar a hipótese de comportamentos esperados, em relação a características de gênero, por parte das mulheres, das quais espera-se uma atitude menos conflituosa e mais submissa, lidando com conflitos de maneira a resolvê-los sem causar maiores desconfortos.

A respeito de como se sentiram em relação à experiência, $18,3 x \%(n=19)$ dos participantes responderam "nada assustados", enquanto a maioria dos participantes relatou que se sentiram um pouco assustados $(57,7 \%, n=60)$ e $24 \%(n=25)$ muito assustados. Esses dados permitem uma reflexão a respeito do parâmetro muitas vezes estabelecido como definição da experiência de stalking, que exige uma reação de medo ou sensação de ameaça por parte da vítima. Os resultados desse estudo mostram que aproximadamente um quarto das pessoas que vivenciaram uma experiência de assédio persistente não se sentiram assustadas como resposta à mesma, o que corresponde aos resultados encontrados em Portugal, nos quais $25 \%$ dos participantes alegaram ter se sentido muito assustados com a experiência e $43,4 \%$ um pouco assustados, enquanto $32,8 \%$ dos participantes não se sentiram assustados (MATOS et al., 201 1a, p.52).

O medo é um aspecto bastante variável e subjetivo. Segundo Hochschild (1983 apud DIETZ; MARTIN, 2007), medo - como outras muitas emoções - é socialmente produzido. Algumas situações geram sentimentos de medo mais do que outras - e isso acontece por diversas razões. Como pode ser visto na Tabela 3, na qual se pretendeu relacionar o sexo da vítima com a forma com que a mesma se sentiu com a experiência, a maioria das mulheres $(62,7 \%, n=52)$ se sentiu "um pouco assustada", enquanto $26,5 \%(n=22)$ se sentiu "muito assustada". Por sua vez, a maior 
parte dos homens $(47,6 \%, n=10)$ relatou ter se sentido "nada assustado", ao passo que $38,1 \%(n=$ 8) ficou "um pouco assustado".

No que diz respeito ao medo causado pela experiência, os resultados do estudo realizado por Beth Bjerregaard (2000), corroborando os dados aqui encontrados, apresentaram uma maior tendência das mulheres a sentirem-se afetadas pelas situações de stalking em comparação aos homens, frente aos dados de que, enquanto apenas $20,7 \%$ dos homens relataram temer por sua segurança física, mais da metade das mulheres o fizeram. É importante pensarmos esses resultados através de uma perspectiva de gênero, na qual as mulheres estão mais expostas a diversas formas de violência cotidianas relacionadas ao fato de serem mulheres do que os homens - como é o caso dos altíssimos índices de estupro e violência doméstica no Brasil. ${ }^{4}$

Além disso, resultados de estudos como o realizado por Dietz e Martin (2007), mostraram que "sentir medo" difere até mesmo entre as próprias mulheres, considerando os resultados apresentados pelos autores, nos quais mulheres negras relatam sentir medo com menos frequência que as mulheres brancas, e mulheres com educação superior relatam sentir mais medo se comparadas a mulheres com ensino médio ou com menor formação. Este trabalho não pretende se aprofundar especificamente na questão do medo, mas vê-se importante ressaltar que tais resultados necessitam ser contextualizados, em uma perspectiva interseccional, considerando as diferentes vivências de mulheres negras e mulheres brancas na sociedade.

A maior parte dos participantes $(62,5 \%, n=65)$ não procurou nenhum tipo de ajuda. De acordo com Grangeia e Matos (2012, p. 33), devido à falta de conhecimento sobre o que é o stalking - muitas vezes fruto da falta de reconhecimento social - as vítimas acabam por ter dificuldade em reconhecer o mesmo, o que, consequentemente, adia a busca por ajuda e a atuação de profissionais competentes.

Tabela 3 - Relação entre sexo da vítima e como se sentiu com a experiência de stalking

\begin{tabular}{lccccc}
\hline & \multicolumn{5}{c}{ Como se sentiu com a experiência } \\
\cline { 2 - 6 } Sexo & & Nada assustado & Um pouco & Muito & Total \\
assustado & assustado & \\
\hline \multirow{2}{*}{ Feminino } & $n$ & 09 & 52 & 22 & 83 \\
& $\%$ & 10,8 & 62,7 & 26,5 & 100,0 \\
\multirow{2}{*}{ Masculino } & $n$ & 10 & 8 & 3 & 21 \\
& $\%$ & 47,6 & 38,1 & 14,3 & 100,0 \\
\hline \multirow{2}{*}{ Total } & $n$ & 19 & 60 & 25 & 104 \\
& $\%$ & 18,3 & 57,7 & 24,0 & 100,0 \\
\hline
\end{tabular}

Por fim, buscou-se, também, relacionar o sexo e a forma/intensidade que a experiência de stalking afetaram a vida do sujeito (Tabela 4). A maior parte das mulheres $(36,6 \%, n=30$ ) relatou que a saúde psicológica foi "um pouco" afetada, $21,7 \%(n=18)$ "muito" afetada e 20,5\% ( $n=17)$ "muitíssimo" afetada. Nesse mesmo aspecto, a maior parte dos homens $(38,1 \%, n=8)$ relatou que a experiência de stalking "não afetou" a saúde psicológica, enquanto $23,8 \%(n=5)$ se sentiu "quase nada" afetada. Cabe, portanto, ressaltar que, ao se somar as categorias avaliadas nas quais as mulheres se sentiram "muito ou muitíssimo afetadas" psicologicamente, percebe-se que o dado corresponde à maioria das participantes - fato distinto da maioria dos homens.

Já em relação ao estilo de vida/comportamento, 29,6\% $(n=24)$ das mulheres foram "um pouco" afetadas, $18,5 \%(n=15)$ "muitíssimo" afetadas, enquanto $24,7 \%(n=20)$ relataram não terem sido "nada" afetadas. A maioria dos homens $(52,4 \%, n=11)$ declarou ter sido "um pouco" afetada.

\section{Considerações finais}

Há muito mais a ser pensado e discutido em relação aos comportamentos de stalking. Os resultados aqui obtidos têm como objetivo, primeiramente, levantar questionamentos sobre a

\footnotetext{
${ }^{4}$ No Brasil, são 606 casos de violência doméstica e 164 estupros por dia - apenas entre números registrados, sendo necessário considerar a subnotificação. (Disponível em: https://www1 .folha.uol.com.br/cotidiano/2018/08/brasil-registra606-casos-de-violencia-domestica-e-164-estupros-por-dia.shtml).
} 
Tabela 4 - Relação entre sexo da vítima e a interferência da experiência de stalking em relação à saúde psicológica

\begin{tabular}{lccccccc}
\hline & \multicolumn{5}{c}{ Interferência em relação a saúde psicológica } \\
\cline { 3 - 8 } Sexo & $n$ & Não afetou & Quase nada Um pouco & Muito & Muitíssimo & Total \\
\hline \multirow{2}{*}{ Feminino } & $n$ & 11 & 07 & 30 & 18 & 17 & 83 \\
& $\%$ & 13,3 & 8,4 & 36,1 & 21,7 & 20,5 & 100,0 \\
\multirow{2}{*}{ Masculino } & $n$ & 08 & 05 & 03 & 03 & 02 & 21 \\
& $\%$ & 38,1 & 23,8 & 14,3 & 14,3 & 9,5 & 100,0 \\
\hline \multirow{2}{*}{ Total } & $n$ & 19 & 12 & 33 & 21 & 19 & 104 \\
& $\%$ & 18,3 & 11,5 & 31,7 & 20,2 & 18,3 & 100,0 \\
\hline
\end{tabular}

definição de stalking, assim como quais suas características, e de que forma se apresenta em indivíduos da população brasileira - considerando-se um fator limitante o número de participantes e a restrição da amostragem, pois os sujeitos que participaram desta pesquisa foram estudantes universitários, e os resultados podem vir a apresentar divergências em caso de se reaplicar a pesquisa em participantes da população geral.

Com isso, pretende-se incentivar reflexões e pesquisas relacionadas ao tema, visto que se trata de um conceito ainda muito discutido e pouco definido, até mesmo na literatura internacional, e que as limitações relacionadas aos participantes, como citado, permitem que a pesquisa aqui realizada se apresente apenas como um passo inicial na discussão empírica sobre o tema no Brasil.

Por dizer respeito a um fenômeno com escassez de estudos nacionais, o termo stalking foi mantido em seu idioma original ou traduzido como assédio persistente, seguindo a literatura portuguesa. Mostra-se importante, também, ressaltar a complexidade do tema, suas diversas nuances e todos os debates que o cercam em toda a literatura internacional, tanto no meio acadêmico, quanto no que diz respeito aos termos legais.

Os resultados encontrados nesse estudo apontaram para uma relevante prevalência da vitimização por stalking em estudantes universitários, o que remete a uma necessidade de se voltar maior atenção ao fenômeno, visto as possíveis consequências e os impactos psicológicos e sociais das experiências de vitimização. É importante que a população saiba sobre o assunto para que seja possível identificar as situações e agir sobre as mesmas da maneira que se mostrar necessário. Como apresentado, no Brasil, o crime de stalking não está tipificado na legislação. Apesar da existente proposta de acrescentá-lo ao Novo Código Penal, há poucas pesquisas nacionais nas quais se basear - e basicamente todo conteúdo existente é produzido pela área do Direito. É importante, também, questionar o que se pretende com a criminalização de comportamentos tão dificilmente definíveis. Punir algo ainda tão pouco estudado nacionalmente e permeado por tantos debates, é realmente uma solução eficaz?

De acordo com uma pesquisa realizada pelo Instituto Avon em parceria com o Data Popular em novembro de 2014, a cada 5 mulheres jovens 3 já vivenciaram violência em relacionamentos. O mesmo estudo aponta para índices elevados de naturalização dessa violência - quando associada a agressão física, $8 \%$ das mulheres assumem terem sofrido violência do parceiro e $4 \%$ dos homens reconhecem já terem tido atitudes violentas contra suas companheiras; já frente a exemplos de outras atitudes como ameaçar, xingar, humilhar, controlar, impedir de usar uma roupa específica ou de sair de casa etc., $55 \%$ dos homens assumiram já terem tido tais comportamentos, enquanto $66 \%$ das mulheres relatam terem sofrido alguma dessas ações por parte do companheiro. Entre 2001 e 201 1, anteriormente à tipificação do crime de feminicídio, ${ }^{5}$ é aferido que tenham ocorrido mais de 50 mil assassinatos de mulheres (AGÊNCIA PATRÍCIA GALVÃO, 2016).

Esses dados se mostram importantes frente aos resultados que foram apresentados nesta pesquisa - as mulheres como maiores vítimas em situações de stalking na amostra utilizada, corroborando com a literatura internacional. Diversas vezes, a experiência de stalking se apresenta

${ }^{5}$ Feminicídio:

$\mathrm{VI}$ - [homicídio] contra a mulher por razões da condição de sexo feminino:

§ 2o-A Considera-se que há razões de condição de sexo feminino quando o crime envolve:

I - violência doméstica e familiar:

II - menosprezo ou discriminação à condição de mulher. (LEI No 13.104, DE 9 DE MARÇO DE 2015. Disponível em: http://www.planalto.gov.br/ccivil_03/_Ato2015-2018/2015/Lei/L13104.htm) 
como prévia a crimes muito mais graves, chegando a culminar em violência sexual e até mesmo feminicídio. É importante também ressaltar os resultados desse estudo que demonstraram a saúde psicológica como área de maior impacto da experiência de stalking para as vítimas - sendo que $20,2 \%$ relataram terem sido "muito afetadas" nesse aspecto.

Dessa forma, sugere-se que maiores pesquisas relacionadas aos comportamentos, aos impactos, a prevalência, dentre outros fatores importantes abordados neste trabalho sejam realizadas a partir das diferentes áreas como a psicologia e as ciências sociais, de forma a se pensar intervenções eficazes e políticas públicas que englobem a problemática do stalking de forma efetiva.

\section{Referências}

ABRAMSON, Kate. "Turning up the lights on gaslighting". Philosophical Perspectives, Ethics, n. 28, p. 1-30, 2014.

AGÊNCIA PATRÍCIA GALVÃO. "Dados e fatos sobre violência contra as mulheres", 2016. Disponível em http://agenciapatriciagalvao.org.br/violencia/dados-e-pesquisas-violencia/dados-e-fatossobre-violencia-contra-as-mulheres/. Acesso em 23/03/2017.

BAUM, Katrina; CATALANO, Shannan; RAND, Michael; ROSE, Kristina. Stalking Victimization in the United States. National Crime Victimization Survey. Washington, DC: U.S. Department of Justice, jan. 2009. p. 1-16.

BJERREGAARD, Beth. "An Empirical Study of Stalking Victimization". Violence and Victims, v. 15, n. 4, p. 389-406, 2000.

BJÖRKLUND Katja; HÄKKÄNEN-NYHOLM, Helinä; SHERIDAN, Lorraine; ROBERTS, Karl. "The Prevalence of Stalking Among Finnish University Students". Journal of Interpersonal Violence, v. 25, n. 4, p. 684689, abr. 2010.

BOURDIEU, Pierre. A dominação masculina. Rio de Janeiro: Bertrand Brasil. Tradução: Maria Helena Kuhner, 1998.

BRASIL. Lei n. 11.340, de 7 de agosto de 2006. "Dispõe sobre mecanismos para coibir a violência doméstica e familiar contra a mulher". Casa Civil da Presidência da República, Brasília, 2006. Disponível em http://www.planalto.gov.br/ccivil_03/_ato2004-2006/2006/lei/l1 1340.htm. Acesso em 23/03/2017.

BRASIL. Assembleia Legislativa. "Projeto de Lei Complementar PLC 5419/2009. Acrescenta o art. 146-A ao Decreto-Lei n 2.848, de 7 de dezembro de 1940 - Código Penal, dispondo sobre o crime de perseguição 'stalking'”. 2009. Disponível em: http://www.camara.gov.br/proposicoesWeb/ prop_mostrarintegra;jsessionid=2C34D6E8 1 1 C8C46B32661B1CC1CD2BC9.proposicoesWeb2?co dteor $=664484 \&$ filename $=$ Tramitacao-PL+5419/2009. Acesso em: 23/03/2017.

CAMARA dos deputados. "PL 5419/2009". Disponível em http://www.camara.gov.br/proposicoesWeb/ fichadetramitacao?idProposicao=438638. Acesso em 23/03/2017.

CAPUTO, Andrea. "Cultural Models Shaping Stalking from a Content Analysis of Italian Newspapers". Europe's Journal of Psychology, v. 9, n. 3, p. 443-460, mai. 2013.

DIETZ, Noella A.; MARTIN, Patricia Yancey. "Women Who Are Stalked: questioning the fear standard". Violence Against Women, v. 13, n. 7, p. 750-776, jul. 2007.

DUTTON, Leila B.; WINSTEAD, Barbara A. "Types, Frequency, and Effectiveness of Responses to Unwanted Pursuit and Stalking". Journal of Interpersonal Violence, v. 26, n. 6, p. 1129-1156, fev. 2011.

FARNHAM, Frank. R.; JAMES, David V.; CANTRELL, Paul. "Association between violence, psychosis, and relationship to victim in stalkers". The Lancet, v. 355, n. 9199, p. 199, jan. 2000.

FLATLEY, John; KERSHAW Chris; SMITH Kevin; CHAPLIN, Rupert; MOON, Debbie. Crime in England and Wales: findings from the British Crime Survey and police recorded crime. London: Home Office, 2010.

GOLDSWORTHY, Terry; RAJ, Matthew. "Stopping the stalker: Victim responses to stalking". Griffith Journal of Law \& Human Dignity. v. 2, n. 1, p. 171-198, mai. 2014.

GRANGEIA, Helena; MATOS, Marlene. "Riscos associados ao stalking: violência, persistência e reincidência". Revista da Sociedade Portuguesa de Psiquiatria e Psicologia da Justiça, v. 5, p. 2948, 2012. 
LAGARDE, Marcela. "El género, fragmento literal: La perspectiva de género". In: LAGARDE, Marcela. Género y feminism. Desarollo humano y democracia. Espanha: Ed. Horas y HORAS, 1996. p. 13-38.

LAMBERT, Eric G.; SMITH, Brad; GEISTMAN, James; CLUSE-TOLAR, Terry; JIANG, Shanhe. "Do men and women differ in their perceptions of stalking: an exploratory study among college students". Violence and Victims, v. 28, n. 2, p. 195-209, 2013.

MARQUES, Silvia P.; PACHECO, Fernanda C. de P. "Refletindo sobre a violência doméstica contra a mulher". Investigação, v. 9, n. 1, p. 55-62, jan/abr. 2009.

MATOS, Marlene; GRANGEIA, Helena; FERREIRA, Célia; AZEVEDO, Vanessa. Inquérito de Vitimação por Stalking: Relatório de Investigação. Braga: Grupo de Investigação sobre Stalking em Portugal (GISP), 2011 a.

MATOS, Marlene; GRANGEIA, Helena; FERREIRA, Célia; AZEVEDO, Vanessa. Stalking: Boas práticas no apoio à vítima. Manual para profissionais. Violência de Género. Lisboa: Comissão para a Cidadania e Igualdade de Género, $2011 \mathrm{~b}$.

MINISTÉRIO DA JUSTIÇA, Itália. "Stalking”. 2014. Disponível em https://webstat.giustizia.it/ Analisi\%20e\%20ricerche/2014\%20-\%20Rilevazione\%20procedimenti\%20di\%20Stalking.pdf. Acesso em 21/03/2017.

MONTEIRO, Claudete F. de S.; SOUZA, Ivis E. de O. "Vivência da violência conjugal: fatos do cotidiano". Texto Contexto Enferm, v. 16, n. 1, p. 26-31, jan/mar. 2007.

ROSENFELD, Barry. "Violence risk factors in stalking and obsessional harassment: a review and preliminary meta-analysis". Criminal Justice and Behavior, v. 31, n. 1, p. 9-36, fev. 2004.

SINCLAIR, H. Colleen; FRIEZE, Irene Hanson. "Initial Courtship Behavior and Stalking: How Do We Draw the Line?" Violence and Victim, v. 15, n. 1, p. 23-40, fev. 2000.

SHERIDAN, Lorraine. P.; BLAAUW, Eric; DAVIES, Graham M. "Stalking: knowns and unknowns". Trauma Violence Abuse, v. 4, n. 2, p. 148-162, abr. 2003.

SPITZBERG, Brian; CUPACH, William. "The State of the Art of Stalking: Taking Stock of the Emerging Literature". Aggression and Violent Behavior, v. 12, n. 1, p. 64-86, 2007.

TJADEN, Patricia; THOENNES, Nancy. "Stalking in America: Findings from the National Violence against Women Survey". Research in Brief, p. 1-19, abr. 1998.

WELLER, Michelle; HOPE, Lorraine; SHERIDAN, Lorraine. "Police and Public Perceptions of Stalking: The Role of Prior Victim-Offender Relationship". Journal of Interpersonal Violence, v. 28, n. 2, p. 320-339, set. 2012.

Mariana Tordin Boen (marianatboen@gmail.com) é graduada em Psicologia pela Universidade São Francisco, pós-graduanda em Criminologia e Direito Penal pelo Instituto de Criminologia e Política Criminal em parceria com o Centro Universitário Uninter e mestranda em Ciências Sociais - Políticas Públicas. Realizou intercâmbio acadêmico na Universidade do Minho, em Portugal e possui experiência como estagiária na Delegacia Especializada em Atendimento à Mulher.

Fernanda Luzia Lopes (fernanda.luzia@usf.edu.br) é psicóloga, mestre e doutora em Psicologia pela Universidade São Francisco. Docente do curso de Psicologia da Universidade São Francisco e da FAE Centro Universitário. Docente do curso de pós-graduação Lato Sensu em Psicologia do Trânsito da Universidade São Francisco.

\section{COMO CITAR ESSE ARTIGO DE ACORDO COM AS NORMAS DA REVISTA}

BOEN, Mariana Tordin; LOPES, Fernanda Luzia. "Vitimização por stalking: um estudo sobre a prevalência em estudantes universitários". Revista Estudos Feministas, Florianópolis, v. 27, n. 2 , e50031, 2019. 


\section{CONTRIBUIÇÃO DE AUTORIA}

Mariana: concepção, coleta de dados, elaboração do manuscrito, redação, discussão dos resultados.

Fernanda: análise de dados, coleta de dados, revisão de manuscrito.

FINANCIAMENTO

Não se aplica.

CONSENTIMENTO DE USO DE IMAGEM

Não se aplica.

APROVAÇÃO DE COMITÊ DE ÉTICA EM PESQUISA

CAAE: 53659116.5 .0000 .5514

CONFLITO DE INTERESSES

Não se aplica.

LICENÇA DE USO

Este artigo está licenciado sob a Licença Creative Commons CC-BY Internacional. Com essa licença você pode compartilhar, adaptar, criar para qualquer fim, desde que atribua a autoria da obra.

\section{HISTÓRICO}

Recebido em 12/04/2017

Reapresentado em 14/11/2018

Aprovado em 07/12/2018 